http://jurnaltarbiyah.uinsu.ac.id/index.php/raudhah

e-mail: jurnalraudhah@uinsu.ac.id

p-ISSN: 2338-2163

e-ISSN: $2716-2435$

\title{
Penanaman Nilai Moral (Religius) Anak Usia Dini Melalui Shalat Dhuha Di Tk IT Muhandis Aceh Tenggara
}

\author{
${ }^{1}$ Hamidatun Nisa Tambak \\ UIN Sunan Kalijaga Yogyakarta \\ email: nisatambak2@gmail.com \\ ${ }^{2}$ Fatmawati, M.Pd \\ UIN Sunan Kalijaga Yogyakarta \\ email: Fatwawati5@gmail.com
}

Article received : 20 Agustus 2021

Article accepted : 11 Oktober 2021
Review process : 20 September 2021

Article published : 01 Desember 2021

\begin{abstract}
Abstrak
Kuisioner dalam penelitian ini terdiri dari 15 item pernyataan tentang penerapan shalat dhuha dan 20 item pernyataan tentang perkembangan moral anak usia dini. Pengumpulan data dalam penelitian ini dilakukan dengan cara menyebarkan kuisioner kepada para responden yang telah terpilih sebagai sampel penelitian. Selanjutnya, setelah responden mengisi kuisioner tersebut, lalau dikumpulkan kembali dan dilakukan analisis. Pada penerapan shalat dhuha ada 2 indikator yang diukur, yaitu indikator pemberian kebebasan (pembolehan yang sifatnya toleran), proteksi (tidak ada hubungan apabila anak melanggar peraturan serta kurangnya control terhadap prilaku dan kegiatan anak sehari-hari) dan indikator yang kedua adalah submission (penyerahan). sebesar $38,75 \%$. Hal ini menunjukkan bahwa pemahaman keagamaan memiliki hubungan yang "sedang" dalam pembentukan moral anak usia dini di TKIT Muhandis Aceh Tenggara perkembangan moral anak dapat disimpulkan bahwa penanaman keagamaan yang permisif memiliki hubungan yang "sedang" dengan nilai rata-rata sebesar 38,75\%. Sedangkan pekembangan moral anak usia dini di TK IT Muhandis juga memiliki kategori "sedang" dengan nilai rata-rata sebesar 59,99\%.
\end{abstract}

Kata Kunci: Penerapan shalat dhuha, Moral (religius), Anak Usia Dini.

\begin{abstract}
The questionnaire in this study consisted of 15 statement items about the implementation of the dhuha prayer and 20 statement items about the moral development of early childhood. Data collection in this study was carried out by distributing questionnaires to the respondents who had been selected as research samples. Furthermore, after the respondents filled out the questionnaire, they were collected again and analyzed. In the implementation of the dhuha prayer, there are 2 indicators that are measured, namely the indicator of giving freedom (tolerant permission), protection (no relationship if the child violates the rules and lack of control over the behavior and daily activities of the child) and the second indicator is submission (submission). ). by 38.75\%. This shows that religious understanding has a "moderate" relationship in the moral formation of early childhood at TKIT Muhandis Aceh Tenggara. It can be concluded that permissive religious cultivation has a "moderate" relationship with an average value of $38.75 \%$. Meanwhile, the moral
\end{abstract}


http://jurnaltarbiyah.uinsu.ac.id/index.php/raudhah

e-mail: jurnalraudhah@uinsu.ac.id

p-ISSN: 2338-2163

e-ISSN: $2716-2435$

development of early childhood at TKIT Muhandis also has a "medium" category with an average value of $59.99 \%$.

Keywords: Implementation of dhuha prayer, Moral (religious), Early Childhood

\section{A. PENDAHULUAN}

Pendidikan merupakan suatu proses yang sangat penting untuk meningkatkan kecerdasan, keterampilan, mempertinggi budi pekerti, memperkuat kepribadian, dan mempertebal semangat kebersamaan agar dapat membangun diri sendiri dan bersama sama membangun bangsa. Disamping itu pendidikan merupakan masalah yang penting bagi manusia, karena pendidikan menyangkut kelangsungan hidup manusia. Usia dini merupakan masa keemasan (golden age). Masa dimana segala pertumbuhan dan perkembangan terjadi. Salah satu perkembangan yang paling penting adalah perkembangan moral anak. Hal ini dikarenakan moral yang dimiliki oleh anak, akan berpengaruh terhadap tata cara anak bersikap dimasa dewasa atau tua nanti.

Pendidikan nilai dan moral yang dilakukan sejak usia dini diharapkan pada tahap perkembangan selanjutnya anak akan mampu membedakan baik buruk, benar salah, sehingga ia dapat menerapkannya dalam kehidupan sehari-hari. Hal itu akan berpengaruh pada mudah tidaknya anak diterima oleh masyarakat sekitarnya dalam hal bersosialisasi. Pendidikan nilai dan moral sejak usia dini merupakan tanggung jawab bersama semua pihak terutama pihak keluarga atau orang tua.

Peran orang tua sangat berpengaruh serta lingkungan tempat tinggal sangat berpengaruh pada perkembangan moral anak. Apakah anak akan memiliki moral yang kokoh ataupun sebaliknya, dengan kata lain moralitas anak bisa dibina sejak dini. Moral itu sendiri diartikan sebagai kesusilaan, tabiat dan kelakuan. Interaksi orang tua pada anaknya tentunya sangat mempengaruhi perkembangan moral anak. Karena pada dasarnya perkembangan moral anak itu tidak bisa terjadi secara cepat. Akan tetapi perkembangan moral pada anak itu berjalan secara bertahap. Sesuai dengan prinsip perkembangan, dimana perkembangan moralnya harus terlewati dengan sempurna. Perkembangan moral pada anak itu harus dibiasakan sejak dini. Sesuai dengan teori perkembangan moral Kohlberg, perkembangan moral diawali dari Moralitas Prakonvensional, moralitas konvensional, dan diakhiri dengan tingkatan Moralitas post konvensional Fikriyati, (2013:128-130). Itu semua bisa dilihat dari bagaimana pola asuh yang diterapkan oleh orang tua dalam menanamkan moralitas. Penataan lingkungan fisik dan psikologis orang tua dapat mempengaruhi moralitas anak. Orang tua sebagai pembimbing bisa mempengaruhi perkembangan moral pada anak.

Nilai Regilius merupakan dasar-dasar yang dapat menentukan gambaran dari kepribadian seseorang yang ditunjukkan melalui sikap dan prilaku terhadap dirinya sendiri serta baagaimana ia 
http://jurnaltarbiyah.uinsu.ac.id/index.php/raudhah

e-mail: jurnalraudhah@uinsu.ac.id

p-ISSN: 2338-2163

e-ISSN: 2716-2435

memperlakukan orang lain dengan baik. Anak-anak bisa saja tumbuh dan berkembang dengan nilainilai yang memiliki perbedaan dari nilai yang orang tua berikan dan apa yang diajarkan oleh guru juga berbeda kepada anak, maka anak akan mengalami kebingungan. Anak lahir seperti kertas putih yang masih polos tanpa adanya coretan tinta Hampir setiap hari muncul berbagai permasalahan terkait kekerasan, pelanggaran hak asasi manusia, tawuran pelajar, berbicara kurang sopan bahkan ada anak yang tidak segan membunuh orangtuanya dan sebagainya. Pemerosotan nilai moral pada anak semakin menjadi-jadi. Narvaez (2014:23)

Shalat sunah duha adalah shalat sunah yang dikerjakan pada waktu dhuha artinya pagi antara pukul 7 sampai 11 siang dengan melakukan sholat dhuha anak-anak pastinya akan melafatkan ayatayat suci Al-Qur'an karena hukum pelaksanaan salat duha adalah sunah, pelaksanaannya dimulai ketika matahari mulai tinggal seukuran satu tombak hingga tergelincir dan yang lebih utama dilakukan setelah seperempat siang. Waktu awal salat duha adalah sekitar 15 menit setelah matahari terbit. Waktu yang paling Afdhal menurut mayoritas ulama di akhir waktunya sekolah merupakan tempat anak memperoleh pengetahuan dan pengalaman secara nyata.Abdurrahman (1990: 14) Guru seyogiyanya mengintegrasikan dan memadukan pendidikan berdasarkan Nilai-nilai religius untuk anak usia dini agar anak lebih peka dengan kesopanan apalagi dengan keadaan yang sekarang ini dimana dunia semakin lama semakin berkembang anak-anak lebih banyak menghabiskan waktunya dengan menggunakan gajet orang tua di jaman sekarang ini juga lebih membiyarkan anak nya bermain dengan gajet dan kurang dalam bersosialisasi dengan teman-teman yang sebaya denganya. Untuk penanaman regilius untuk anak guru di TKIT Muhandis Aceh Tenggara mengajarkan anakanak ilmu-ilmu agama dengan mengajak anak sholat dhuha sebelum pembelajaran berlangsung. Arikunto (2009: 15)

Berdasarkan observasi yang dilakukan peneliti, pelaksanaan salat dhuha ini dikatakan unik atau berbeda dari taman kanak-kanak pada umumnya. Disebabkan anak yang telah lulus dari Taman Kanak-Kanak (TKIT) ini menjadi lebih pandai dalam melaksanakan salat dhuha dan baik dalam bacaan salatnya daripada semua taman kanak-kanak yang juga melaksanakan pembelajaran yang seperti ini yaitu pembiasaan salat dhuha, dan anak juga akan memahami bagaimana tatacara dalam melakukan sholat sunat maupun shalat wajib.Agus salim (2006:55) Pendidikan merupakan suatu proses yang sangat penting untuk meningkatkan kecerdasan, keterampilan, mempertinggi budi pekerti, memperkuat kepribadian, dan mempertebal semangat kebersamaan agar dapat membangun diri sendiri dan bersama sama membangun bangsa. Disamping itu pendidikan merupakan masalah 
http://jurnaltarbiyah.uinsu.ac.id/index.php/raudhah e-mail: jurnalraudhah@uinsu.ac.id

p-ISSN: 2338-2163

e-ISSN: 2716-2435

yang penting bagi manusia, karena pendidikan menyangkut kelangsungan hidup manusia untuk masa yang akan datang. Permendiknas( 2009:34)

\section{B. METODE PENELITIAN}

Pada penelitian ini peneliti menggunakan metode penelitian korelasional dengan analisis kuantitatif. Iskandar (2008:24) “penelitian korelasi sering disebut penelitian hubungan sebab akibat (kausal korelation). Tujuan penelitian ini adalah untuk mengetahui hubungan antara dua variabel atau lebih, atau hubungan variabel bebas dan variabel terikat.

Sesuai permasalahan yang diangkat pada penelitian ini adalah permasalahan yang menghubungkan dua variabel.Amiruddin (2016:108) Hubungan variabel dalam penelitian adalah hubungan kausal, yaitu hubungan yang bersifat sebab akibat. Hubungan variabel yang dimaksud disini adalah penanaman spiritual anak untuk perkembangan moral anak usia dini TKIT Muhandis Aceh Tenggara. Populasi dari penelitian ini yaitu guru dan anak yang bersekolah di TKIT Muhandis. Berdasarkan hasil pengamatan orang tua yang menyekolahkan anaknya di TKIT Muhandis di Aceh Tenggara berjumlah 97 orang, terdiri dari 20 orang yang pemahaman spiritual yang dalam, 12 orang tua dengan pemahaman spritual yang sedang dan 65 orang tua dengan pemahaman spirutual yang kurang. Hapsari I Iriani(2016:23)

Teknik Analisis Data Dalam penelitian ini menggunakan Uji Prasyarat Statistik, Uji Normalitas, Uji normalitas dimaksudkan dalam penelitian ini untuk mengetahui apakah data yang akan dianalisis berbentuk sebaran normal atau tidak, dengan kata lain sampel dari populasi yang berbentuk data berdistribusi normal atau tidak. Pada penelitian ini pengujian normalitas digunakan untuk menguji data variabel $\mathrm{X}$ dan variabel $\mathrm{Y}$. Langkah yang ditempuh dalam melakukan uji normalitas adalah dengan uji chi kuadrat berikut:

$$
x^{2}=\sum\left[\frac{(f o-f h)}{f h}\right]
$$

Keterangan :

$$
\begin{array}{ll}
x^{2} & =\text { chi kuadrat } \\
\text { fo } & =\text { kebiasaan yang diperoleh } \\
f h & =\text { kebiasaan yang diharapkan }
\end{array}
$$

Apabila harga $x^{2}{ }_{\text {hitung }}<x^{2}{ }_{\text {tabel }}$ maka data yang diperoleh berdistribusi normal, sebaliknya bila $x_{\text {hitung }}^{2}<x_{\text {tabel }}^{2}$ maka data yang diperoleh tidak berdistribusi normal. 
http://jurnaltarbiyah.uinsu.ac.id/index.php/raudhah e-mail: jurnalraudhah@uinsu.ac.id

p-ISSN: 2338-2163

Uji linearitas digunakan untuk melihat apakah spesifikasi model yang digunakan dapat diterima atau tidak. Uji linearitas dimaksudkan untuk melihat apakah variabel yang dihubungkan itu berbentuk linear atau diartikan bahwa setiap penambahan yang terjadi pada satu variabel akan diikuti dengan besaran yang sejajar dengan variabel lainnya. Rumus dari uji linearitas ini adalah :

$$
F_{\text {hitung }=\frac{R_{j k}(t c)}{R_{j k}(E)}}, F_{\text {tabel }=(1-a)(k-2 ; n . k)}
$$

Jika Jika nilai $F_{\text {hitung }}<F_{\text {tabel }}$ maka Ho diterima berarti persamaanya linier, sedangkan jika nilai $F_{\text {hitung }} F_{\text {tabel }}$ maka Ho ditolak berarti persamaanya tidak linier.

Uji korelasi adalah suatu teknik statistik yang dipergunakan untuk mengukur kekuatan hubungan variabel dan juga untuk dapat mengetahui bentuk hubungan antara dua variabel tersebut dengan hasil yang sifatnya kuantitatif.

$$
\mathrm{r}=\sqrt{\left[\mathrm{n} \Sigma \mathrm{x}^{2}-(\Sigma \mathrm{x})^{2}\right) \mathrm{I} n \Sigma \mathrm{y}^{2}-(\Sigma \mathrm{y})^{2}}
$$

Dimana :

$$
\begin{array}{ll}
\mathrm{n} & =\text { Jumlah data (responden) } \\
\mathrm{x} & =\text { Shalat dhuha } \\
\mathrm{y} & =\text { Pemahaman Spiritual }
\end{array}
$$

Menurut sugiyono (2017) pedoman untuk memberikan interpretasi koefisien korelasi adalah sebagai berikut :

\section{Tabel 1. Interpretasi Koefisien Korelasi}

\begin{tabular}{|c|l|}
\hline Interval Koefisien & Tingkat Hubungan \\
\hline $0,00-0,299$ & Sangat rendah \\
$0,20-0,199$ & Rendah \\
$0,40-0,699$ & Sedang \\
$0,60-0,999$ & Kuat \\
$0,80-1,000$ & Sangat kuat \\
\hline
\end{tabular}

\section{HASIL TEMUAN DAN PEMBAHASAN}

\section{Deskripsi Data Penelitian}

Hasil penelitian mengenai shalat dhuha (X) dengan variabel perkembangan moral anak usia dini (Y) di Tkit Muhandis Aceh Tenggara diperoleh berdasarkan ukuran yang kuat dengan keeratan hubungan antara variabel mengenai shalat dhuha dengan variabel perkembangan moral anak usia dini.Hasil penelitian menunjukkan bahwa penanaman moral dikalangan masyarakat masih sangat minim sehingga memiliki hubungan yang "sedang" terhadap 
http://jurnaltarbiyah.uinsu.ac.id/index.php/raudhah

e-mail: jurnalraudhah@uinsu.ac.id

p-ISSN: 2338-2163

e-ISSN: $2716-2435$

perkembangan moral anak usia dini, sedangkan perkembangan moral anak usia dini di TKIT Muhandis Aceh Tenggara berada pada kategori "sedang". Sehingga dapat dikatakan bahwa perkembangan moral anak usia dini di TK Muhandis Aceh Tenggara berkembang dengan baik.

Berdasarkan hasil analisis korelasi penelitian diperoleh nilai $\mathrm{r}$ pearson correlation sebesar 0,580 menyatakan besarnya derajat keeratan hubungan antara variabel pola asuh dengan perkembangan moral anak. Hal ini menunjukkan bahwa hubungan antara pola asuh dengan perkembangan moral anak menunjukkan hubungan yang sedang. Hal ini seusai dengan pendapat Sugiyono (2017) bahwa nilai korelasi dari variabel X terhadap variabel Y apabila berada pada rentan nilai 0,40-0,599 maka dapat dikategorikan bahwa hubungan tersebut berada pada kategori sedang seperti penjelasa tabel dibawah ini.

Tabel 2. Uji Normalitas

One-Sample Kolmogorov-Smirnov Test

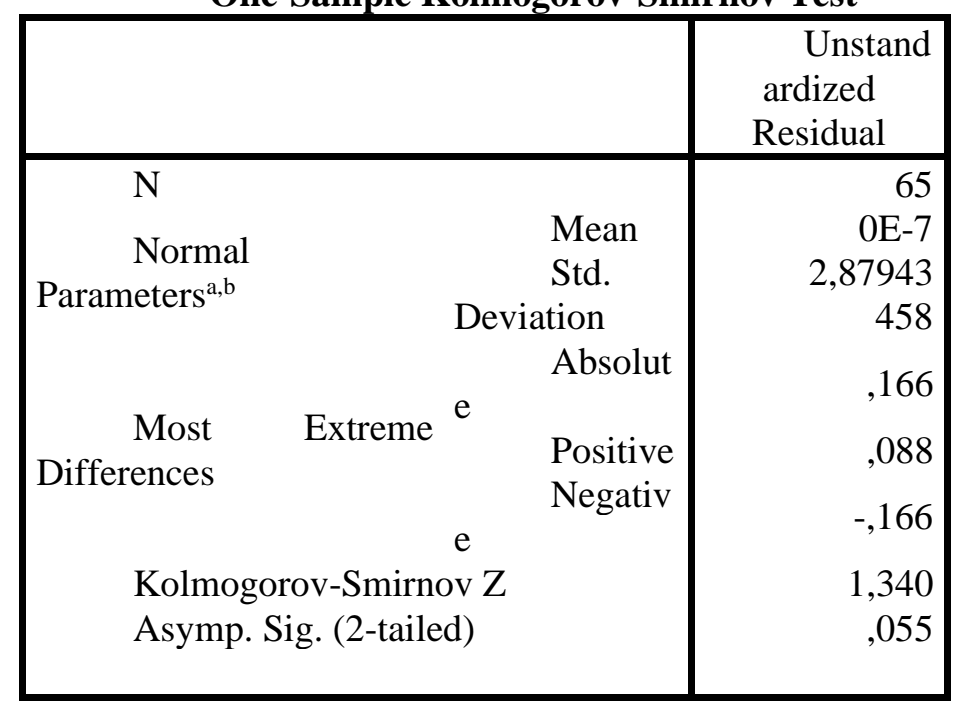

Penanaman moral kepada anak usia dini yang diterapkan dalam penelitian ini adalah melalui shalat dhuha, walaupun dirumah anak-anak masih longgar melakukan shalat dhuha dua rokaa'at.maka dari itu orang tua memberikan kesempatan kepada anaknya untuk melakukan sesuatu tanpa pengawasan yang cukup darinya. Terkadang orang tua dirumah cenderung tidak menegur atau memperingatkan anak apabila anak sedang dalam bahaya, dan sangat sedikit bimbingan yang diberikan oleh mereka. Orang tua tipe ini serin sehingga sering disukai oleh anak Madyawati, (2016:37-39). 
http://jurnaltarbiyah.uinsu.ac.id/index.php/raudhah

e-mail: jurnalraudhah@uinsu.ac.id

p-ISSN: 2338-2163

e-ISSN: 2716-2435

Perkembangan moral adalah aturan atau tata cara hidup untuk menentukan perubahan penalaran, perasaan, dan perilaku tentang standar mengenai benar dan salah. Kurangnya moral anak dan pemahaman agamanya memiliki hubungan yang rendah terhadap perkembangan moral anak usia dini. Hal ini dikarenakan perkembangan moral anak sangat tergantung pada anak tersebut baik di lingkungan sekolah, keluarga maupun masyarakat.

Menurut Soetjiningsih (1995) dalam Risaldy hubungan orangtua dan anak adalah suatu bentuk interaksi timbal balik antara orangtua dan anak maka hubungan ini di wujudkan dengan sikap dan perilaku orangtua terhadap anak. Terutaman pada pola asuh keluarga sangat berpengaruh terhadap pembentukan karakter anak. Setiap keluarga biasanya memiliki pola asuh terhadap anak yang berbeda beda. Pola asuh juga berpengaruh terhadap keberhasilan keluarga dalam mentransfer dan menanamkan nilai nilai agama, kebaikan, norma-norma yang berlaku dalam masyarakat.

Penelitian ini dilakukan untuk mengetahui penanaman keagamaan (Spritual) untuk anak usia dini di TKIT Muahandis Aceh Tenggara. Keagamaan yang dilihat dari penelitian ini adalah penanaman keagaman yang rendah. Dalam penelitian ini, peneliti menyiapkan instrumen penelitian dalam bentuk kuisioner berdasarkan landasan teori yang ada. Kuisioner dalam penelitian ini terdiri dari 15 item pernyataan tentang penanaman keagamaan (Spiritual yang rendah dan 20 item pernyataan tentang penerapan sholat dhuha anak usia dini. Pengumpulan data dalam penelitian ini dilakukan dengan cara menyebarkan kuisioner kepada para responden yang telah terpilih sebagai sampel penelitian. Selanjutnya, setelah responden mengisi kuisioner tersebut, lalau dikumpulkan kembali dan dilakukan analisis. Pada saat shalat dhuha belangsung ada 2 indikator yang diukur, yaitu indikator pemberian kebebasan (pembolehan yang sifatnya toleran), proteksi (tidak ada hubungan apabila anak melanggar peraturan serta kurangnya control terhadap prilaku dan kegiatan anak sehari-hari) dan indikator yang kedua adalah submission (penyerahan). Sedangkan pada perkembangan agama (Spiritual), indikator yang diukur adalah kemampuan anak untuk berprilaku sesuai dengan anjuran agama yang dianut, berprilaku sopan dan peduli melalui perkataan dan perbuatannya serta kemauan anak untuk menolong orang lain. Berdasarkan indikator tersebut, maka distribusi data dari penanaman spiritual melalui shalat dhuha dapat dilihat pada Tabel 3. berikut :

\begin{tabular}{|l|l|l|l|l|l|l|l|}
\hline No & Kode & $\mathbf{X}$ & $\%$ & No & Kode & X & $\%$ \\
\hline
\end{tabular}


http://jurnaltarbiyah.uinsu.ac.id/index.php/raudhah e-mail: jurnalraudhah@uinsu.ac.id

p-ISSN: 2338-2163

\begin{tabular}{|c|c|c|c|c|c|c|c|}
\hline 1 & FL & 14 & 21,00 & 36 & A & 12 & 18,46 \\
\hline 2 & AS & 13 & 20,00 & 37 & $S$ & 14 & 21,57 \\
\hline 3 & AR & 13 & 20,00 & 38 & YS & 12 & 18,44 \\
\hline 4 & ND & 15 & 23,08 & 39 & SY & 11 & 16,90 \\
\hline 5 & $\mathrm{NH}$ & 10 & 15,38 & 40 & BS & 9 & 13,86 \\
\hline 6 & EK & 10 & 15,38 & 41 & NK & 15 & 23,09 \\
\hline 7 & MSG & 10 & 15,38 & 42 & WF & 12 & 18,48 \\
\hline 8 & $\mathrm{~J}$ & 11 & 16,92 & 43 & IW & 14 & 21,50 \\
\hline 9 & IR & 11 & 16,92 & 44 & $\mathrm{AR}$ & 10 & 15,36 \\
\hline 10 & $\mathrm{HN}$ & 11 & 16,92 & 45 & JI & 15 & 23,09 \\
\hline 11 & YB & 12 & 18,46 & 46 & I & 12 & 18,45 \\
\hline 12 & $\mathrm{~K}$ & 12 & 18,46 & 47 & I & 12 & 18,48 \\
\hline 13 & $\mathrm{~N}$ & 12 & 18,46 & 48 & DSS & 12 & 18,49 \\
\hline 14 & YK & 10 & 15,38 & 49 & $\mathrm{FN}$ & 11 & 16,93 \\
\hline 15 & $\mathrm{~K}$ & 12 & 18,46 & 50 & $P$ & 12 & 18,47 \\
\hline 16 & JK & 11 & 16,92 & 51 & JK & 14 & 21,59 \\
\hline 17 & $\mathrm{H}$ & 13 & 20,00 & 52 & EW & 13 & 20,00 \\
\hline 18 & I & 12 & 18,46 & 53 & $S$ & 14 & 21,54 \\
\hline 19 & $\mathrm{O}$ & 11 & 16,92 & 54 & $\mathrm{DS}$ & 13 & 20,00 \\
\hline 20 & $\mathrm{SC}$ & 13 & 20,00 & 55 & BY & 13 & 20,00 \\
\hline 21 & JK & 15 & 23,08 & 56 & AR & 10 & 15,37 \\
\hline 22 & WS & 10 & 15,38 & 57 & DV & 14 & 21,56 \\
\hline 23 & WD & 13 & 20,00 & 58 & $\mathrm{R}$ & 13 & 20,00 \\
\hline 24 & YB & 14 & 21,54 & 59 & SA & 13 & 20,00 \\
\hline 25 & $\mathrm{SH}$ & 11 & 16,92 & 60 & $S$ & 11 & 16,92 \\
\hline 26 & $\mathrm{MG}$ & 12 & 18,46 & 61 & $\mathrm{MI}$ & 13 & 20,00 \\
\hline 27 & PD & 14 & 21,54 & 62 & JR & 14 & 21,54 \\
\hline 28 & VB & 11 & 16,92 & 63 & $S$ & 11 & 16,92 \\
\hline 29 & B & 15 & 23,08 & 64 & FI & 13 & 20,00 \\
\hline 30 & KA & 13 & 20,00 & 65 & $S$ & 13 & 20,00 \\
\hline 31 & WY & 15 & 23,08 & \multicolumn{3}{|c|}{ Rata-Rata } & $\mathbf{3 8 , 7 5}$ \\
\hline 32 & A & 12 & 18,46 & & & & \\
\hline 33 & $\mathrm{Y}$ & 13 & 20,00 & & & & \\
\hline 34 & $\mathrm{~F}$ & 14 & 21,54 & & & & \\
\hline
\end{tabular}

Dari tabel 3. di atas menunjukkan bahwa nilai rata-rata sebesar 38,75\% dengan begitu penerapan Shalat dhuha memiliki hubungan yang "sedang" dalam pembentukan moral anak usia dini di TK IT Muhandis Aceh Tenggara. 
http://jurnaltarbiyah.uinsu.ac.id/index.php/raudhah

e-mail: jurnalraudhah@uinsu.ac.id

p-ISSN: 2338-2163

e-ISSN: 2716-2435

\section{SIMPULAN}

Shalat sunah duha adalah shalat sunah yang dikerjakan pada waktu dhuha artinya pagi antara pukul 7 sampai 11 siang dengan melakukan sholat dhuha anak-anak pastinya akan melafatkan ayat-ayat suci AlQur'an karena hukum pelaksanaan salat duha adalah sunah, pelaksanaannya dimulai ketika matahari mulai tinggal seukuran satu tombak hingga tergelincir dan yang lebih utama dilakukan setelah seperempat siang Kuisioner dalam penelitian ini terdiri dari 15 item pernyataan tentang penerapan shalat dhuha dan 20 item pernyataan tentang perkembangan moral anak usia dini. Pengumpulan data dalam penelitian ini dilakukan dengan cara menyebarkan kuisioner kepada para responden yang telah terpilih sebagai sampel penelitian. Selanjutnya, setelah responden mengisi kuisioner tersebut, lalau dikumpulkan kembali dan dilakukan analisis..Penelitian ini dilaksanakan di TK IT Muhandis Aceh Tenggara. Anak usia dini mempunyai sifat meniru terhadap apapun yang di lihatnya. Masa ini adalah masa yang sangat rentan karena anak akan memperhatikan, mengingat dan melakukan apa yang telah dilakukan oleh orang terdekatnya, terutama kedua orang tua. Oleh sebab itu, orang tua harus menerapkan pola asuh yang tepat agar perkembangan moral anak dapat berkembang dengan baik.Tujuan dari penelitian ini adalah mengetahui penerapan sholat dhuha dengan perkembangan moral (Spiritual) anak usia dini di TKIT tersebut. Berdasarkan hasil penelitian diperoleh nilai $r$ pearson correlation sebesar $0,59(\mathrm{P}>0,05)$. Hal ini menunjukkan bahwa pengajaran keagamaan orang tua yang permisif berhubungan dengan perkembangan moral (Spiritual) anak usia dini di TKIT Muhandis Aceh Tenggara dengan kategori hubungan "sedang".

\section{DAFTAR PUSTAKA}

Abdurrahman. Cara Praktis Mengatasi Perkembangan Anak. 1990.

agus salim. Teori Dan Paradigma Penelitian. 2006.

Amiruddin, Amiruddin. ““'Internalisasi Nilai-Nilai Agama Pada Anak Usia Dini Di Raudhathul Atfhal Perwanida 1 Lipu Kabupaten Majene.” Al-Qalam 20, No. 1 (2016): 109.

arikunto. Penelitian Tindakan Kelas. 2009.

Fikriyati, Mirroh. Perkembangan Anak Usia Emas (Golden Age). Yogyakarta: Laras Media Prima, 2013.

Hapsari I Iriani. .. Psikologi Perkembangan Anak. Jakarta Barat: PT Indeks, 2016.

Iskandar. Metodologi Penelitian Pendidikan Dan Sosial (Kuantitatif Dan Kualitatif). 2008. Narvaez., Nucci \&. Handbook Pendidikan Moral Dan Karakt[1] N. \& Narvaez., Handbook

Pendidikan Moral Dan Karakter. Bandung: Penerbit Nusa Media, 2014. .Er. Bandung: Penerbit Nusa Media, 2014.

Permendiknas. Standar Kompetensi Lulusan Pendidikan. Jakarta: Pusat Perbukuan 
http://jurnaltarbiyah.uinsu.ac.id/index.php/raudhah e-mail: jurnalraudhah@uinsu.ac.id

p-ISSN: 2338-2163

e-ISSN: 2716-2435

Departemen Pendidikan Nasiona. 2009. 